\title{
Effect of the Queensland Shark Control Program on non-target species: whale, dugong, turtle and dolphin: a review
}

\author{
N. A. Gribble, G. McPherson and B. Lane ${ }^{A}$ \\ Northern Fisheries Centre, PO Box 5396, Cairns, Qld 4870, Australia. \\ ${ }^{A}$ Queensland Shark Control Program, Mineral House, George St, Brisbane, Qld 4000. Australia
}

\begin{abstract}
The Queensland Shark Control Program (QSCP) has recorded a long-term annual mortality of 0.1 humpback whale, 2 'small whales' (species uncertain), 20 dugong, $<78$ turtles (species and number released uncertain), and $<19$ dolphin (species and number released uncertain). Available population estimates suggest that the historic impact of the QSCP would have been negligible on whales, $0.5 \%$ per year of the dugong population in the southern Great Barrier Reef, minor on green and loggerhead turtle populations, and unknown but probably minor on leatherback turtles and dolphin populations. In response to improved methods between 1992 and 1995 the average yearly mortality fell to 0 humpback whales, 4 dugong, 3 loggerhead turtles (11 turtles in total), and 10 dolphin (species uncertain); this suggests no impact on whales, $0.1 \%$ per year of the dugong population of the southern Great Barrier Reef, $1.6 \%$ of the yearly indigenous harvest of green turtles in eastern Australia, and $0.2 \%$ per year of the loggerhead turtle population in Queensland. Lack of population estimates and species identification precluded impact calculations for dolphin. The number of rare, vulnerable and endangered marine animals killed in the QSCP gear each year is in tens rather than thousands and the effect of this incidental mortality on their populations is probably minor.
\end{abstract}

Extra keywords: capture of non-target species.

\section{Introduction}

The Queensland Shark Control Program (QSCP) aims to protect swimmers at ten beach areas on the east coast of Queensland between Cairns $\left(17^{\circ} \mathrm{S}\right)$ and the Gold coast $\left(28^{\circ} \mathrm{S}\right)$. Since its inception in 1962 it has deployed shark nets and baited drumlines in a 'mixed gear strategy' that adapts the type of gear to the characteristics of a site (e.g. extreme tidal range, high energy wave action, or proximity of turtle breeding areas). The policy has provided swimmer protection, and the incidental capture of non-target species has been lower than that resulting from deployment of nets alone (Dudley 1997; Gribble et al. 1998b). The QSCP is the only major public-safety shark-control program to routinely use mixed gear. Both the New South Wales (Holt 1998) and KwaZulu-Natal (Dudley 1998) programs use nets exclusively, although the KwaZulu-Natal program has recently tested drumlines on an experimental basis (Dudley 1998; Dudley, personal communication).

In 1996 the QSCP set 37 shark nets and 292 baited drumlines, with drumlines deployed at four protected areas and a combination of nets plus drumlines deployed at the other six areas; there was a combined maximum of $6882 \mathrm{~m}$ of shark net $(37 \times 186 \mathrm{~m})$, which is $<0.4 \%$ of the coastline between Cairns and the Gold Coast. Each protected area consists of a number of beaches, and at each beach there are normally 1-3 nets (each $186 \mathrm{~m}$ long) and up to six drumlines. QSCP shark nets are not designed as a barrier but as a fishing device to reduce the number of large sharks in a local area. The opera- tion of QSCP has been described and the basic catch statistics reported in Paterson $(1979,1986)$ and in McPherson et al. (1998), with a comparison of the operation and catches of the three major shark control programs, the KwaZulu-Natal Shark Board, NSW Shark Meshing Program, and the QSCP published in Dudley (1997). A more detailed time-series of the catch of non-target species by the QSCP has been described in Paterson (1990).

Initiatives (Table 1) were begun by the QSCP in 1992 to reduce capture of non-target species, in response to recommendations of a ministerial Committee of Enquiry (Anon. 1992). In 1996-97 a second Committee of Enquiry was formed to investigate the effect of the QSCP on vulnerable and endangered species (as defined in the various Acts), particularly the outcomes of the initiatives put forward in $1992 / 93$. The present paper is in response to the needs of the second committee and to interest at an international workshop (Gribble et al. 1998a).

\section{Methods}

Basic data set

(source: QSCP database, assembled from daily records of shark contractors and irregular records from the Marine Rescue Squads)

See Paterson $(1979,1986,1990)$ for a summary of the QSCP data up to 1988. Present deployment of shark control gear is shown in Fig 1. The catch and catch-per-unit-effort data since 1988 is presented here only in summary form. All catch and effort data were re-entered into the computer database and validated from original contractor records. Where possible, anomalies on original records were checked and identification of locations was standardised in consultation with the respective contractor. 
Table 1. Major initiatives by the QSCP in response to recommendations from the 1992 Committee of Enquiry into the operation and maintenance of shark-meshing equipment in Queensland waters

- Replacement in late 1992 of QSCP shark nets at all Rockhampton beaches and at Horseshoe Bay, Townsville, with baited drumlines to reduce capture of non-target species in those areas. (Implimented after consultation with local user groups (subsequently formalized into QSCP focus groups))

- Since 1992/3: inclusion of reduction of incidental capture of endangered species (and their live release if taken accidentally) as a priority.

- A Code of Practice with regard to capture of non-target species has been incorporated into contracts for QSCP contractors.

- Full reporting of non-target species is required in the daily logs filled out by contractors. Since 1992/3, complete details on the capture of non-target species have been recorded; previously, only numbers of each species category caught were reliably recorded.

- Procedures for the safe release of large marine animals from QSCP nets and drumlines have been documented and distributed to officers in all QSCP areas.

- Annual meeting/training workshops for QSCP shark contractors. Experts on endangered species give presentations to heighten contractors' awareness of these species. Workshops are also held on procedures for the safe release for large marine animals.

- Marine Rescue Squads, involving representatives of QSCP, Queensland Boating \& Fishing Patrol, Queensland Department of Environment (QDoE), Surf Life Saving Association, and SEA WORLD staff, have been set up progressively since 1993 to handle safe release of large marine mammals.

- Local Focus Groups were set up in 1993 at each of the ten areas where the QSCP operates gear. These community liaison groups are kept informed of the catch statistics for their area, including capture of non-target species, and are consulted about the future directions of the program.

- A public awareness education program was started in 1993 with the production and distribution of an educational videotape about shark control, information pamphlets on safe bathing, and five identification posters of the main species of shark that occur in Queensland waters. The program continues.

- A scientific evaluation/comparison was carried out on the catch of nets and drumlines (including the capture of non-target species) and presented at the 1995 QSCP shark contractors' annual meeting/workshop with summaries circulated to all interested groups.

- Research was initiated in 1992/3 into the feasibility of sonic 'warning' beacons (Whale Alarms) to be fitted to QSCP nets on the Gold Coast to counter the possibility of accidental entanglement of migrating humpback whales. No whales were entangled in nets with beacons fitted and there was no significant drop in the shark catch. Alarms are now routinely fitted to nets on the Gold and Sunshine Coasts.

- A feasibility study was initiated in 1994/95 for sonic 'warning' beacons (Harbour Porpoise 'pingers') to be fitted to all QSCP nets to reduce the accidental entanglement of dolphins. Testing with commercially available 'pingers' (DUKAINE Corp.) is underway at Cairns.

- Research was initiated in 1992/3 into redesign of QSCP gear to further reduce accidental capture of endangered species, by (a) changes in hook design to reduce incidental capture of loggerhead turtles and (b) changes in net design to reduce the incidental capture of all turtles.

- Co-operative projects were initiated by the QSCP with external research programs involving endangered species, principally with C. Limpus studying the movement and feeding patterns of loggerhead turtles. Contractors now regularly tag and release turtles caught in QSCP gear. Dolphin carcasses when available from the northern region are shipped to researchers at James Cook University, Townsville.

- QSCP sponsored and organized the 'Sharks and Man: shark management and conservation' workshop, held under the auspices of the 2nd World Fisheries Congress in Brisbane, 1996. The objectives of the shark-control component of this international workshop were to explore ways to maintain bather safety while reducing the capture of endangered species.

Assessment of the effect of the QSCP on each major category of by-catch comprises a summary of the QSCP database catch information and a summary of the literature on population estimates (if available), the logic used in the assessment, and lists the measures in place to reduce the effect on by-catch. Mortality estimates were calculated in two ways: a simple average annual mortality across the full time-series of the dataset, and the average annual mortality from 1992 to 1995 when improved recording of by-catch was available.

The general term 'threatened' is used to describe species that are listed as rare, vulnerable or endangered in either Queensland or Australian Federal legislation.

\section{Constraints on impact analysis}

1. The QSCP has focussed on the taking of large sharks considered dangerous to humans; hence, reporting was mainly for project management not for scientific data collection. For the majority of the catch and effort timeseries, sharks and by-catch were recorded by taxonomic group rather than by species; however, better identification and reporting has been available since 1992/93 (see Table 1).

2. The capture of non-target species has been recorded for the full 34 years of the program but with less detail than for the target shark species. Before 1992 the data are limited to the general categories of whale, dugong, turtle, and dolphin. Turtles, in particular, only began to be separated reliably into species after identification kits and tagging equipment were distributed in 1992.

3. Within the database there are three categories of gear; net, drum, and unknown.

4. In the early records, the condition of non-target species was not recorded; hence, the database has the categories 'alive', 'dead' and 'unknown'. The categories 'dead' and 'unknown' have been grouped as 'mortality' in the present analysis, although a splitting of the 'unknowns' into a ratio of dead and alive might have been more realistic. An animal caught in the nets or on drumlines is not necessarily dead; QSCP contractors have had a policy of releasing non-target species alive if possible, and this policy has been reinforced since 1992 .

5. In the case of Point Lookout, where there was a replacement of nets with drumlines in 1979, the contractor has identified loggerhead turtles as the majority of turtles taken before 1992. Therefore it was possible to backestimate the catch of this species at this site over a 16-year period. (Green turtles are herbivorous and are rarely taken on baited drumlines except when when a hook accidentally snags them.)

6. In 1962-63, there was considerable experimentation with gear. Initially, bottom-set, monofilament nets were used, but these were rapidly replaced by surface-set, 'venetian blind cord' nets (E. M. Grant, ex-QDPI Fisheries and originator of the QSCP, personal communication). Nets were standardized on the latter type from then until 1996. Therefore initial catch rates, although included in the present analysis for completeness, are not truly comparable with later data. 


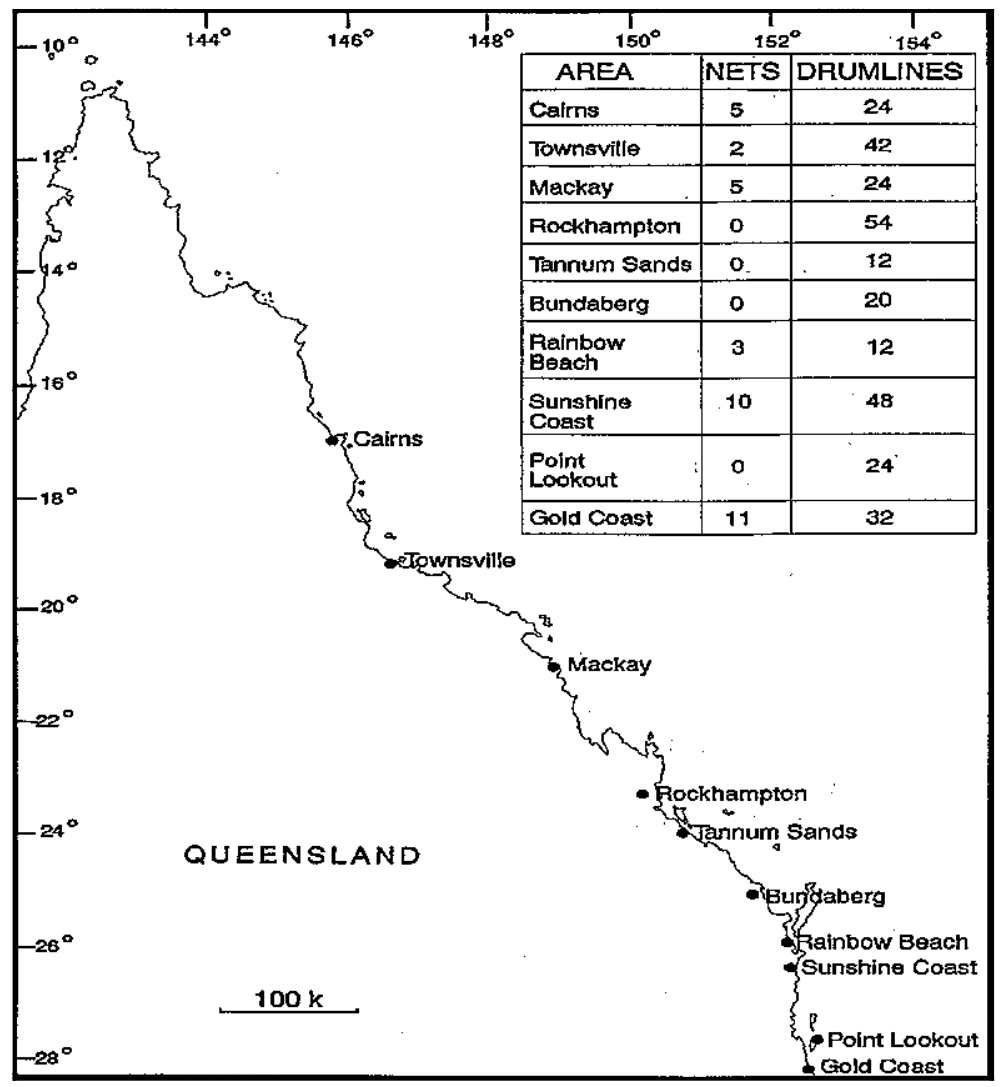

Fig. 1. Map showing 1996 deployment of QSCP shark control gear along the east coast of Queensland.

Table 2. Average annual mortality of non-target species categories recorded by the QSCP

Numbers refer to animals recorded as dead or 'condition unknown'

\begin{tabular}{lcc}
\hline Species (Common name) & $\begin{array}{c}1962-95 \\
\text { yearly average }\end{array}$ & $\begin{array}{c}1992 / 3-1995 \\
\text { yearly average }\end{array}$ \\
\hline Humpback Whale & 0.1 & 0 \\
Small whales $^{\mathrm{A}}$ & 2 & 0 \\
Dugong & $20^{\mathrm{B}}$ & 4 \\
Dolphin & $19^{\mathrm{B}}$ & 10 \\
Turtle & $78^{\mathrm{B}}$ & $11^{\mathrm{C}}$ \\
\hline
\end{tabular}

${ }^{\wedge}$ Species unknown. ${ }^{\mathrm{B}}$ Captured, fate unknown. ${ }^{\mathrm{C}}$ On average, 3 specimens of the endangered loggerhead turtle, 8 not identified.

\section{Analysis and Results}

Since 1992, the mortality (encompassing 'dead' and 'condition unknown') of rare, vulnerable and endangered nontarget species has fallen (Table 2). Animals released alive by the program from $1992 / 93$ to 1995 comprised $100 \%$ of the whales, $17 \%$ of dugong, $13 \%$ of dolphins and $87 \%$ of turtles ( $90 \%$ of the endangered loggerhead turtles).

\section{Whales}

'Whale' includes humpback, pilot and minke whales, and at least one false killer whale. Most of the reports of whale catches at centres other the Gold Coast and Sunshine Coast were in the early years of the program. These reports tend to be of multiples of two or three individuals (possibly indicating pods) and hence suggest the capture of pilot whales or possibly mis-identified large dolphins.

Humpback whales. According to the QSCP database, 8 whales were captured during 1962-95 off the Sunshine Coast and Gold Coast, with 5 being released alive and 3 either dead or fate unknown; they were mainly juveniles or calves. Humpback whale, Megaptera novaeangliae, is listed as vulnerable under both State and Federal legislation and is protected. Adults usually avoided the nets but are sufficiently large and powerful to destroy the gear if accidentally entangled. An example of the latter was observed off the Sunshine coast in 1996 (B.L., personal observation). During 1992-95 one additional live release of a humpback was recorded in a separate database maintained for the rapid-response Marine Rescue Squads. Such operations are not included in the QSCP database.

This 'harvest rate' of 1 whale per 10 years is low compared with the estimated recovery rate of $11.7 \%$ per year for the population over the same 30-year period (Paterson et al. 1994). However, there is concern about obstruction of the humpback migration routes by QSCP nets and the potential for accidental entanglements to increase in the future, given that numbers of humpbacks are increasing. 
In 1992, J. Lien (Whale Research Group, Memorial University, Canada) assisted in preliminary testing of "Whale Alarm' sonic beacons based on a device used to warn humpbacks of the presence of cod traps in Newfoundland and Nova Scotia. Initial tests were carried out on selected nets in the Gold Coast and Cairns regions. Paired comparison trials in 1993 showed no significant drop in shark catch due to the fitting of the beacons; therefore, these devices were fitted to all nets on the Gold Coast and in 1995 to the nets on the Sunshine Coast (Lien et al. 1998).

Small whales. Although captures of 'small whales' appear in the early records of the QSCP, the reports cease from 1983 onwards. At Rockhampton, 47 'short-toothed whales' were reported captured during 1969-75. It is likely that the majority of these were mis-identified dolphins, because the last record of the capture of a 'short-toothed whale', in 1975, was just before the then contractor retired; after this date 'irrawaddy dolphin' are recorded but no 'short-toothed' small whales.

Similarly, the single 'killer whale' reported taken at Cairns in 1973 has no parallel in any other QSCP catch. A tooth from the carcass was subsequently sent to the Queensland Museum and identified as coming from Pseudorca crassidens, the false killer whale (Limpus, personal communication).

Excluding humpback whales, 60 other 'whales' were reported in the database. A worst case, where these were all small whales and all these died, would equate to an average harvest of 1.8 animals per year over the duration of the program. In reality, no reliable reports of the capture of small whales by the QSCP have been recorded in the database for the past 20 years. Historically, depletions of local populations along the Queensland coast are possible, but as there are no independent estimates of population numbers or even of the geographic distribution of these species it is impossible to test this hypothesis. A potentially confounding factor would be the effects of coastal whaling (primarily targeting humpbacks) which continued in Queensland until 1962 (Paterson et al. 1994). The conservation status of the small whale species in Queensland is undetermined.

Management measures for small whales are the same as those for dolphins (see below).

\section{Dugong}

Dugong, Dugong dugon, is listed as vulnerable in Queensland legislation and by the IUCN. The QSCP database shows an average of 20.4 animals per year caught during 1962-96, exclusively in nets. The catch rates were higher in the first few years of the program when more nets were in use (Patterson 1990) but reduced to $<4.3$ per year from 1992 to 1995 . During 1992-95, 16.7\% of captured dugongs were released alive, giving an average mortality of 3.8 animals per year.
To estimate the effect of this harvest rate on the dugong population, several assumptions and generalizations were required.

(1) Population estimates based on aerial surveys of the dugong in the southern half of the Great Barrier Reef (GBR) region indicated $3847 \pm 459$ animals (mean \pm s.e.) in 1986 and $1750 \pm 257$ animals in 1994 (Marsh 1995a); the decline was probably due to anthropogenic sources of mortality (Marsh 1995a). For example, land clearance exacerbated sediment runoff during two cyclonic storms in 1992, and this caused a dieback of seagrasses in Hervey Bay and hence a loss of food for the dugongs in the bay (Preen and Marsh 1995).

(2) Historically, the population may have been higher but probably not lower than the 1986 estimate.

(3) The average dugong catch from the QSCP-controlled areas within the southern GBR region (combining Cairns, Townsville, Mackay, Rockhampton, Tannum Sands and Bundaberg) was 18.4 animals per year from 1962 to 1985. On the basis of the 1986 population estimate and an assumption that all captured dugong died, the historic harvest rate or yield of the QSCP would have averaged $0.5 \%$ of the population per year up to 1986 .

(4) During 1994-95 the average dugong catch for controlled areas within the southern GBR region was 1.5 animals per year. (The number of nets in the region had been reduced in 1992 when Rockhampton and Horseshoe Bay (Townsville) were changed to drumlines only.) On the basis of the 1994 estimate of the dugong population (Marsh $1995 a$ ) the present yield of the QSCP is $<0.1 \%$ of the dugong population in the southern GBR per year.

(5) An assessment of the status of the dugong population in the Torres Strait (Marsh et al 1997) suggested that a sustainable yield for that fishery might be $2.5 \%$ of the estimated population. It was impossible to verify this without an understanding of the movements of the dugong population, better absolute estimates of dugong population size, dugong catch statistics for adjacent regions, and estimates of life-history parameters for dugongs.

(6) Even assuming that the estimates of dugong numbers in the southern GBR were approximate, QSCP catch rates of between $0.5 \%$ and $0.1 \%$ of the population fall well below the above estimates of sustainable yield for the dugong population in the Torres Strait.

Estimating the effect QSCP has on local rather than regional populations of dugongs was not possible without a detailed time-series of local population estimates. Marsh (1995b) states that the cause for the apparent increase in the dugong population of the Torres Straits (from 13319 \pm 2136 (mean \pm s.e.) in 1987 to $24225 \pm 3276$ in 1992) was 'most likely due to migration'. Similarly, at least part of the decrease in the dugong population in the Hervey Bay region of the southern GBR between 1986 and 1994 was attributed 
to possible migration of animals out of the region (Preen and Marsh 1995). These data suggest that large movements of dugong populations are possible and might confound any changes in local populations caused by the QSCP. Furthermore, since 1992 the catch rates of dugong by the QSCP have been so low $(<4.3$ animals per year from all areas statewide), that random variation ('chance captures') would make any trend analysis of a local population unproductive.

To reduce the effect of the QSCP on the dugong population, two schemes are being tested. (1) If a dugong is captured in the Cairns region and it is not possible to release it alive, the carcass will be given to the indigenous community. Although tribal elders have agreed to stop dugong hunting within the world heritage area, the provision of these carcasses will maintain a supply for traditional use. (2) 'Dolphin Pinger' sonic beacons are being tested on nets in the Cairns region (see Dolphin section below). There is some evidence, from experiments with captive dugong in Indonesia, that these may also be effective in deterring dugong (J. Lien, personal communication).

\section{Turtles}

The QSCP database capture records show four categories of sea turtles: the generic 'turtle', green turtle, loggerhead turtle, and leatherback turtle. Turtle capture has only recently been divided into these sub-categories. The majority of the historic records refer simply to 'turtle'.

Turtles are caught both in nets and on drumlines but most have been recorded from nets $(30 \%)$ or from 'unknown' gear (62\%). The average yearly capture rate from 1962 to 1995 was 119.4 animals per year. On the basis of interviews with the QSCP contractors, the majority would have been green turtles, caught mainly in the nets, with a smaller number of loggerhead turtles caught mainly on the drumlines. During $1962-95,35 \%$ of turtles were released alive and for $59 \%$ the condition was not recorded.

During 1992-96 the QSCP capture rate has averaged 84 turtles of all species per year but $87 \%$ of these were released alive (i.e. 11 turtles per year were either dead or condition unknown). Green turtles in particular tend to become entangled in the upper section of the nets and hence survive well until they can be released.

Green turtles. The green turtle, Chelonia mydas, is listed as vulnerable under Queensland legislation. Assessing the effect of the QSCP 'harvest' on green turtle populations is difficult because no time-series of overall population estimates is available. At worst, if all the turtles captured and not recorded as released alive by the QSCP were green turtles and all these died, the harvest rate since 1962 would have been 78 animals per year. In comparison, the harvest taken by indigenous peoples is $\sim 5000$ green turtles annually in Queensland waters (Limpus, personal communication) and $~ 5000$ (mostly large females) annually in the Torres Strait (Williams 1994).
Studies of DNA have shown discrete breeding populations of green turtles within the Indo-Pacific region (Norman et al 1994). There are two such breeding populations in Queensland; a northern-GBR stock deriving from the Raine I. and adjacent island nesting beaches, and a southern-GBR stock deriving from the nesting beaches of the Capricornia islands (Limpus, personal communication). The QSCP catch of green turtles would be primarily from the southern-GBR stock, and an estimate of the impact on this population would assist management; however, this is dependent on better population estimates becoming available.

Loggerhead turtles. The loggerhead turtle, Caretta caretta, is listed as endangered by Queensland and Australian Federal legislation. The estimated number of nesting loggerhead turtles in Queensland in 1991 was 1000 females (Limpus and Reimer 1992; Heppell et al. 1996). Assuming a sex ratio of $1: 1$, the conservative lowest population estimate would be 2000 animals. The actual population would be larger because loggerheads nest only every third year (i.e. there would be three times as many females as indicated) and the sex ratio of the loggerhead has been skewed towards males by predation on the mainland where temperatures at the nesting sites result in predominantly female eggs (Heppell et al. 1996).

During 1992-95, an average of 28.5 loggerhead turtles per year have been captured by the QSCP but $90 \%$ have been released alive. Although the Point Lookout turtle catch was entered onto the QSCP database simply as 'turtle', it is now known that these were loggerheads and the present analysis has corrected for this. On the basis of the 1991 estimate of the number of nesting loggerhead turtles and assuming a 1:1 sex ratio, the QSCP 'yield' between 1992 and 1995 would have been $0.14 \%$ per year.

Since 1993, contractors have tagged turtles before release. Some turtles return to baited drumlines to feed, and these individuals have been recaptured and released on a number of occasions; one recalcitrant individual has been recaptured 24 times so far. It is possible that repeated hooking of a turtle may cause death at a later time, even if it is successfully released alive after each recapture. A number of loggerhead turtles have been damaged by hooks to such an extent that the contractor has not released them but has arranged to get them to Sea World on the Gold Coast for treatment and convalescence. Of the 11 treated since 1992, 9 have survived to be released, although one of these died 12 months later (T. Long, Sea World Enterprises, personal communication). Hence, the database records may over-estimate the number caught because the same individuals can be captured a number of times; however, this overestimate may be offset by a higher mortality of these released individuals, due to hook damage. Imprecise mortality estimates have been allowed for in the present analysis by using a worst-case estimate of mortality and a conservative minimum estimate of 
the population in the yield calculations. In a harvest fisheries sense, a yield of $<0.2 \%$ of the population per year would have a minor impact on a stock, even for species with a dependence on high adult survivorship.

Leatherback turtles. The leatherback turtle, Dermochelys choriacea, is listed as endangered by Queensland and as vulnerable by Federal legislation. Very little could be gained from the literature on population estimates for this species of turtle in Queensland waters. The QSCP database records 25 leatherback turtles captured during 1962-96 with 15 released alive $(60 \%)$. Most of these were recorded after 1992 and probably reflect an increased awareness on the part of the contractors. Given the very low numbers caught it is not possible to speculate as to the impact the QSCP may have on the species.

Management. Turtles have the best survival rate of any non-target species captured by the QSCP gear. However, two directions are being explored to reduce their accidental capture. (l) Because turtles tend to be entangled in the upper section of the nets the contractors have suggested that sinking the headrope of the net by $\sim 0.5 \mathrm{~m}$ may reduce the turtle catch, particularly of green turtles. (2) A special hook based on a tuna hook is being designed to reduce accidental fouling by bait-stealing loggerhead turtles. It is designed to 'set' when taken by a violent 'strike' such as by a large shark.

\section{Dolphins}

The QSCP database has records of 'dolphin', 'irrawaddy dolphin' (Irrawaddy River dolphin), and a single porpoise. Only a small proportion of the catch was identified by contractors as Irrawaddy River dolphin, Orcaecella brevirostris, or the Indo-Pacific humpbacked dolphin, Sousa chinensis; both are listed as rare under the Queensland Nature Conservation Act 1992 but are not listed as threatened under the Australian Endangered Species Act 1992. Identification is improving, with at least the Irrawaddy River dolphin being reliably separated since 1992 . The single porpoise in the database was most likely a mis-reported dolphin, because porpoises do not normally occur off the Queensland coast. The earliest record of the 'irrawaddy dolphin' in the database was in 1968 at Townsville. Interviews with contractors in 1995 suggested that the majority of dolphins caught were bottlenose or common dolphins, neither of which are listed as rare, vulnerable or endangered.

Dolphins are recorded in the QSCP database as captured mainly in nets and rarely on drumlines. The yearly average capture rate of all dolphin species combined was 19.2 animals per year but, as with the dugong, catch rates were high in the first few years of the program (see Paterson 1990) and have reduced to 12.5 animals per year for 1992-95 (1.3 'irrawaddy dolphin' and 11.2 'dolphin'). The percentage of animals recorded as released alive was $13 \%$ but this should improve in future with the efforts of the Marine Rescue
Squads. The actual mortality for 1992-95 of all dolphin species combined was 10.3 animals per year.

Determining the effect of the QSCP is almost impossible without population estimates for the Queensland coastal dolphins, or even a breakdown of the species composition and where they occur. An incidental mortality rate of $0.02(2 \%)$ has been allowed in management of small cetacean species in the USA (Scott 1990; Read et al 1992; see also Wade 1998). For the QSCP capture rate to exceed this level, in the case of the Irrawaddy River dolphin, the population of this species off the Queensland coast would have to be 65 animals or less. Anecdotal reports from commercial fishers and the QSCP contractors indicate a considerably higher abundance.

Taking the worst case where all 10.3 dolphins were from rare species, the total population of these dolphins along the Queensland coast would have to be 515 animals or fewer before the QSCP harvest would exceed the USA 'safe' level. Anecdotal reports indicate that the dolphin populations along the coast are more likely to be in the thousands rather than in the hundreds.

Management. Marine Rescue Squads were formed in south-eastern Queensland in 1992, and subsequently along the coast. Drawn from appropriate local organizations, team members are on 24-h call and are trained in the safe release of large marine animals from nets and drumlines. Sonic warning beacons suitable for cetaceans were tested off Cairns. 'Dolphin pingers' (Dukane Co., USA) are being tested on QSCP nets; these sonic beacons are required by law on set gill-nets in parts of the USA and have been found to reduce capture of non-target harbour porpoise significantly, in some cases by $>50 \%$ (Lien et al. 1995; Kraus et al., in press). Trials of these devices on QSCP nets are continuing.

\section{Discussion}

Analysis of these catch data can give only the likely magnitude of the effect of the QSCP on a broad scale across species groups; detail of the effect on populations in local areas will require explicitly designed research projects.

The annual number of rare, vulnerable or endangered species of marine animals killed by QSCP nets and drumlines is low, and for most species the annual number of these captures relative to the total population is too small to have significant demographic effect. Historic and present mortality rates caused by the QSCP, on its own, would have had a minor effect on the populations of whales, dugong, and turtles. In the case of dolphins, species identification of animals caught in QSCP gear has been uncertain and, consequently, the proportion of the catch that was rare species is unknown; however, the 'worst-case' effect on any one species is unlikely to be major, given the low numbers involved.

The aim of the QSCP is not to indiscriminately kill sharks or non-target species, but to protect bathers at the most 
heavily used bathing beaches in Queensland. The effect of the program on non-target species has to be balanced against the swimmer safety record that has been maintained by the QSCP. Contingency plans involving procedures, education and gear technology aim to reduce the effect of capture of each non-target species while maintaining bather safety. Preliminary data from 1996 and 1997 show that a combination of such measures has further reduced the incidental capture of non-target species (Anon. 1998). Both the 1992 and the 1996 State Government Ministerial Enquiries into the operations of the QSCP established that any changes to the program must be made with due regard to the its primary responsibility, that of protecting human life.

\section{Acknowledgments}

The authors acknowledge the assistance of the QSCP contractors, past and present, their local QB\&FP liaison officers, and the local community Shark Control focus groups. Information on turtle survival was supplied by Sea World Enterprises, Australia. Dr Col Limpus as a reviewer gave many valuable and constructive insights.

\section{References}

Anon. (1992). Review of the operation and maintenance of shark meshing equipment in Queensland waters. Report of the Committee of Enquiry. (Queensland Department of Primary Industries: Brisbane.) $114 \mathrm{pp}$.

Anon. (1998). The Queensland Shark Control Program: Report of the committee of review 1997. (Queens land Department of Primary Industries: Brisbane.)

Dudley, S. F. J. (1997). A comparison of shark control programs of NSW and Queensland (Australia) and KwaZulu-Natal (South Africa). Ocean and Coastal Management 34(1), 1-27

Dudley, S. F. J. (1998). Shark netting in KwaZulu-Natal: an update, and a personal perspective on shark control. In 'Shark Management and Conservation. Second World Fisheries Congress Workshop Proceedings, Brisbane August 1996'. (Eds N. A. Gribble, G. McPherson and B. Lane.) QDPI Conference and Workshop Series No. QC98001, pp. 37-44.

Gribble, N. A., McPherson, G, and Lane, B. (eds) (1998a). 'Shark Management and Conservation.' Second World Fisheries Congress Workshop Proceedings, Brisbane August 1996. QDPI Conference and Workshop Series (QC98001), $143 \mathrm{pp}$.

Gribble, N. A., McPherson, G., and Lane, B. (1998b). Shark control: a comparison of meshing with set drumlines. In 'Shark Management and Conservation. Second World Fisheries Congress Workshop Proceedings, Brisbane August 1996'. (Eds N. A. Gribble, G. McPherson and B. Lane.) QDPI Conference and Workshop Series No. QC98001, pp. 98-124.

Heppel, S., Limpus, C., Crouse, D., Frazer, N., and Crowder, L. (1996). Population model analysis for the loggerhead sea turtle, Caretta caretta, in Queensland. Wildlife Research 23, 143-59.

Holt, S. (1998). The Shark Attack Control Program in New South Wales: the shark species catch, bycatch and administrative processes for the protective beach meshing program in an Australian state. In 'Shark Manage-ment and Conservation. Second World Fisheries Congress Workshop Proceedings, Brisbane August 1996'. (Eds N. A. Gribble, G. McPherson and B. Lane.) QDPI Conference and Workshop Series No. QC98001, p. 36. (Abstract.)

Kraus, S., Read, A., Anderson, E., Baldwin, K., Solow, A., Spradlin, T., and Williamson, J. (in press). A field test of the use of acoustic alarms to reduce incidental mortality of harbour porpoises in gill nets. National Marine Fisheries Service, Technical Document, $28 \mathrm{pp}$.

Lien, J., Lane, B., Gribble, N., and McPherson, G. (1998). Use of acoustic alarms to reduce humpback whale bycatch in shark control gillnets on Queensland's Gold Coast. In 'Shark Management and Conservation. Second World Fisheries Congress Workshop Proceedings, Brisbane August 1996'. (Eds N. A. Gribble, G. McPherson and B. Lane.) QDPI Conference and Workshop Series No. QC98001, pp. 45-46. (Abstract.)

Lien, J., Hood, C., Pittman, D., Ruel, P., Borggard, D., Chisholm, C., Weisner, L., Mahon, T., and Mitchell, D. (1995) Field tests of acoustic devices on groundfish gillnets: assessment of effectiveness in reducing harbour porpoise by-catch. In 'Sensory Systems of Aquatic Mammals'. (Eds R. A. Kastelein, J. A. Thomas and P. E. Nachtigall.) pp. 349-64

Limpus, C. J., and Reimer, D. (1991). Species reviews: loggerheads. In 'Proceedings of the Australian Marine Turtle Conservation Workshop'. pp. 31-59. (Queensland Department of Environment and Heritage: Brisbane.)

Marsh, H. (1995a). Can coastal marine mammals survive in tropical waters? Dugongs in Australia as a case study. In 'Eleventh Biennial Conference on the Biology of Marine Mammals. Orlando Florida. USA'. p. 72. (Abstract.)

Marsh, H. (1995b). Torres Strait dugong 1994, Stock Assessment Report, Torres Strait Fisheries Assessment Group. (Australian Fisheries Management Authority: Canberra.)

Marsh, H., Harris, A. N. M., and Lawler, I. R. (1997). The sustainability of the indigenous dugong fishery in Torres Strait, Australia/Papua New Guinea. Conservation Biology 11(6), 1375-86

McPherson, G., Gribble, N., and Lane, B. (1998). Shark control risk management in Queensland: a balance between acceptable levels of bather safety, public responsibility and shark catch. In 'Shark Management and Conservation. Second World Fisheries Congress Workshop Proceedings, Brisbane August 1996'. (Eds N. A. Gribble, G. McPherson and B. Lane.) QDPI Conference and Workshop Series No. QC98001, pp. 21-34.

Norman, J. A., Moritz, C., and Limpus, C. J. (1994). Mitochondrial DNA control region polymorphisms: genetic markers for ecological studies of marine turtles. Molecular Ecology 3, 363-73

Patterson, R. A. (1979). Shark meshing takes a heavy toll of harmless marine animals. Australian Fisheries (October), 17-23.

Patterson, R. A. (1986). Shark prevention measures working well. Australian Fisheries (March), 12-18.

Patterson, R. A. (1990). Effects of long-term anti-shark measures on target and non-target species in Queensland, Australia. Biological Conservation 52, 147-59.

Patterson R., Paterson P., and Cato D. H. (1994). The status of humpback whales Megaptera novaeangliae in east Australia thirty years after whaling. Biological Conservation 70, 135-42.

Preen A. R., and Marsh, H. (1995). Response of dugongs to large-scale loss of seagrass from Hervey Bay, Queensland, Australia. Wildlife Research 22, 507-19.

Read, A. J., Kraus, S. D., Bisack, K. D., and Palka, D. (1992). Harbour porpoises and gill nets in the Gulf of Maine. Conservation Biology 7(1), 189-93.

Scott, G. P. (1990). Management-oriented research on bottlenose dolphins by the Southeast Fisheries Centre. In 'The Bottlenosed Dolphin'. (Eds S. Leatherwood and R. Reeves.) pp. 623-39. (Academic Press: San Diego, CA.)

Wade, P. R. (1998). Calculating limits to the allowable human-caused mortality of cetaceans and pinnipeds. Marine Mammal Science 14(1), 1-37.

Williams, G. (1994). 'Fisheries and Marine Research in Torres Strait. Sea Turtles.' (Australian Government Publishing Service: Canberra.)

Manuscript received 21 April 1997; revised 12 February, 28 July and 2 November 1998; acepted 2 November 1998 